\title{
DE PASSAGENS E PAISAGENS: GEOGRAFIA E ALTERIDADES EM RUY DUARTE DE CARVALHO
}

\author{
ABOUT TRANSITS AND LANDSCAPES: \\ GEOGRAPHY AND OTHERNESS IN RUY \\ DUARTE DE CARVALHO
}

Rita Chaves / Nazir Ahmed Can*

\section{RESUMO}

O presente artigo reflete sobre a importância do espaço e do deslocamento nas narrativas de Ruy Duarte de Carvalho. Fundamental para o alargamento do território literário angolano, a geografia, em sua obra, convida-nos ainda a repensar o lugar das figuras radicalmente excluídas ao longo dos sucessivos regimes de historicidade. Representando as várias faces da alteridade que Angola ainda guarda, esses lugares e personagens permitem ao autor o escrutínio de velhos e novos poderes e, ao mesmo tempo, a criação de veredas para o pensamento artístico e científico.

PALAVRAS-CHAVE: Ruy Duarte de Carvalho; geografia; alteridades.

\section{ABSTRACT}

This article reflects on the importance of space and displacement in the narratives of Ruy Duarte de Carvalho. Fundamental to the extension of the Angolan literary territory, the geography, in his work, invites us to rethink the place of radically excluded figures in the sucessive regimes of historicity. Representing the many faces of otherness of Angola, these places and characters allow the author to scrutinize the old and new powers and, at the same time, to create new ways for the artistic and scientific thought.

KEYWORDS: Ruy Duarte de Carvalho; geography; otherness. 
Pelos títulos dos livros de Ruy Duarte de Carvalho desenha-se um dos muitos roteiros de leitura que a sua obra sugere. Poeta, ficcionista, cineasta e antropólogo, o intelectual, tão inquieto quanto criativo, de muitas maneiras alerta-nos para a dimensão do espaço em seu projeto literário. Seja na poesia, na narrativa, ou como o próprio designava, nessa "meia-ficção-erudito-poético-viajeira" que soube cultivar, a combinação espaço e deslocamento tornou-se uma dominante: entre Chão de oferta (1972), a primeira publicação, e o inconcluso Paisagens efêmeras, inscrevem-se Como se o mundo não tivesse leste (1977), Ondula, savana branca (1982), Hábito da terra (1988), Lavra (2005), Vou lá visitar pastores (1999) e As paisagens propícias (2005), para citarmos só algumas das obras legadas por ele. Reiterada ao longo dos anos, a referência espacial, insinuando-se ou explicitando-se, aponta a noção geográfica como uma notável cadeia significativa no itinerário de quem via na errância muito mais que um tema.

Para uma compreensão mais funda do significado dessa questão, vale a pena confrontarmos a dimensão do fenômeno em sua obra e na constituição da literatura a que o seu nome se liga. Sim, porque se circunscrevemos o olhar ao plano da literatura, a prevalência do espaço, por si, não causa surpresa, pois é inegável o lugar de relevo de tal elemento estrutural em sistemas intelectuais configurados sob o calor do debate em torno da questão nacional, como se deu com a literatura angolana. Diante de autores como António Cardoso, Arnaldo Santos, José Luandino Vieira, Manuel Rui e Pepetela, nomes significativos no contexto literário do qual não podemos afastar o nome de Ruy Duarte de Carvalho, percebemos o movimento de apropriação da terra invadida que torna visível aquela fome de espaço que, na perspectiva de Antonio Candido (2006, p. 433), animou a literatura brasileira.

Em Angola, sobretudo a partir dos anos 60, os ficcionistas buscariam uma contraposição aos pressupostos da literatura colonial que, empenhada em traduzir no terreno do simbólico a ocupação das terras a que julgava ter direito, apontava para uma "estrutura de sentimento" (SAID, 1999) assente na ideia de superioridade civilizacional. No processo de apropriação colonial, os investimentos carreados para a produção de um repertório literário comprometido com o ponto de vista do invasor tinha entre os objetivos a fixação de um território. Elaborado sob o signo da posse, o mapa que se definia configurava-se na composição de personagens e na construção do enredo. Todavia, na relação com o espaço refletia-se de forma inequívoca a relação entre o sujeito que escreve e o lugar que pretende apreender, na verdade o mundo que se pretendia aprisionar. Para conduzir a operação apresentava-se um narrador firme, seguro, não obstante a dimensão grandiosa da gesta que se atribuía.

Tardia no universo lusitano, a aliança entre a expansão e a escrita foi marcada pela precariedade. Muito diferentemente do que ocorreu nos cenários britânico e francês, em Portugal a relação entre literatura e império nunca foi incisiva. A fragilidade desses laços compõe certamente mais 
uma face da oclusão da sociedade portuguesa, para a qual a alteridade nunca foi mais que uma miragem, distante e perturbadora. Por incompreensível ou por incômodo, o "outro" jamais exerceu um fascínio ou se converteu em motivação. Nesse sentido, pode-se compreender que nas narrativas que compõem o repertório da literatura colonial portuguesa o espaço urbano seja rarefeito, muito embora a maior parte dos colonos ali vivessem. Naquilo que estava fora - ou, antes, longe das cidades - recaía o foco de interesse. Nem mesmo a ideia de campo se projetava, pois o que ressaltava era a selva. Como sucedeu nos sistemas literários britânico e francês, e agora nos referimos às obras produzidas com mais de um século de antecedência (o que apenas confirma o atraso lusitano também no campo de opressão simbólica), instituiu-se o mato como uma espécie de representação primordial da África, como bem argumenta Francisco Noa em seu já clássico Império, mito e miopia (2003).

Sobre esse "mato", mais facilmente poder-se-ia sobrepor a noção de vazio que importava disseminar. Nessa indistinção apoiava-se a ideologia imperial, ancorando-se numa estética que fazia tábula rasa de tudo o que se acumulara antes da "descoberta" pelo olhar europeu. Descrever, classificar, nomear eram etapas funcionais à dominação e a escrita reeditava a sua cumplicidade com a inconclusa expansão. Segundo Edward Said (1999; 2001), nem mesmo o brilho de um escritor como Conrad revelou-se isento à tentação de reconhecer na voz europeia a força legítima do discurso capaz de dar existência às coisas. Em No coração das trevas, obra tão genial quanto polêmica, podemos encontrar:

mas havia um local... o maior, o mais branco, por assim dizer... pelo qual eu ansiava. É verdade que àquela época o espaço já não estava em branco. Tinha sido preenchido, desde a minha puberdade, com rios e lagos e nomes. (CONRAD, 2008, p. 30).

É fácil reparar no peso da autorreferência. O preenchimento data da puberdade de quem fala, quer dizer, é essa a vida a partir da qual montam-se as balizas temporais, negando-se sentido ao que havia sido percorrido por quem ali habitara desde perdidos tempos. Antes da chegada dos europeus, havia apenas o nada. Era essa cultivada crença na capacidade de "inaugurar" tempos e espaços a base da consciência planetária que Mary-Louise Pratt (1999) associa à expansão. Isso explica na literatura colonial a ênfase nos lugares pouco habitados, aos quais caberia o epíteto de "mato", como se reproduz na literatura em língua portuguesa que, por astúcias do poder, também foi chamada de literatura ultramarina.

Em resposta a esse comportamento que delineava o perfil do colonizador lusitano, o colonizado buscará recolocar os termos da complicada equação. No caso angolano, a estratégia foi, então, assentar-se sobre a cidade de Luanda, a velha capital, onde estava alicerçado o eixo do poder que era urgente destronar. Os escritores vão fazer emergir um outro espaço, nitidamente ocupado e no qual se imprimem os traços de uma resistência 
que percorre as ruas e ativa a utopia. Sede da administração, desde o início da idade colonial, Luanda era o palco a ser ocupado, uma ocupação simbólica a anunciar a retomada concreta do chão que o sentimento nacional iria consolidar.

Nessa etapa, vem à cena o livro símbolo: Luuanda $(1965)^{2}$. Nas incontornáveis narrativas que compõem a obra de José Luandino Vieira, vemos surgir outra geografia. As ruas e becos de areia quebram a imagem da África encerrada no mato e também arranham a imagem de uma cidade equilibrada, refletida nos padrões da cidade de asfalto que começava a surgir na literatura colonial, como afirmação do processo civilizatório com que se pretendia justificar a missão portuguesa. Contra essa impostura, no lugar da Cidade Alta e das "ruas de alcatrão", o autor elege a cidade dos colonizados, as ruas sinuosas, os becos refratários à penetração policial. A oposição areia/alcatrão seria recorrente nos contos de Arnaldo Santos, Jofre Rocha e Boaventura Cardoso. Assim se desenvolvia uma espécie de travessia que carreava símbolos, imagens, expressões linguísticas, numa dinâmica que, envolvendo significados e significantes, elaborava uma nova gramática. Os textos que nos legaram esses escritores levam-nos a constatar que, enquanto na literatura colonial havia uma inclinação para a construção de um espaço atemporal, reduzido a partir de uma perspectiva monofocal, na narrativa anticolonial o espaço possui uma profunda vocação histórica, situando-se no plano da metonímia e do dialogismo.

Porque muito bem discutida por estudiosos, entre os quais destaca-se Tania Macêdo (2008), e porque enfatizada em entrevistas de tantos escritores, dispensamo-nos de uma detida análise dos motivos para a centralidade de Luanda na história das letras em Angola. Tais aspectos, todavia, são importantes como base para compreender como Ruy Duarte de Carvalho parte desse lugar para revitalizar a opção pelo espaço como traço de resistência e, mais que isso, como signo da transformação que o ato de olhar e escrever Angola deveria atualizar.

Ao publicar as três narrativas que integram o volume Como se o mundo não tivesse leste, Ruy situa-se fora e distante da cidade capital. Vai buscar outras paisagens. Melhor dizendo, vai reencontrar a paisagem em que viu forjada a sua identidade angolana, por ele sempre interpretada como o sentimento de pertença a um lugar que em nada se assemelhava ao local que assistiu ao seu nascimento biológico. A trajetória em direção ao Sul que se pode notar já no primeiro poema do primeiro livro prossegue nas linhas da prosa que ele aí inicia ${ }^{3}$.

A partir daí, a diversificação, uma das marcas de seu percurso, se vai intensificar. Quem tinha começado pela poesia enveredou pelo cinema e depois da ficção incorporaria a antropologia como mais um meio de conhecer a realidade em que se insere. Paralelamente ao itinerário do país em formação, a travessia de Ruy Duarte de Carvalho mobilizava outros meios para ler e traduzir a sua experiência nesse processo. Um dos resultados na 
escrita seria a mescla de gêneros que ele cultivaria e na qual a articulação espaço/mobilidade encontraria variados modos de expressão. Leitor de Barthes, também defenderia a ideia de que a etnologia é, entre as ciências humanas, a que mais se aproxima da ficção; e ele, pouco dado a mistificações, investiria seu talento na demonstração das singularidades desses laços.

No cruzamento entre literatura e antropologia, a viagem é uma espécie de significante que se desdobra em significados, cada um assumindo no quadro em que surgem várias funções, convergindo, porém, na direção do compromisso com uma ética que se distancia da gratuidade. Desse modo, apenas uma leitura apressada poderia fazer confundir os propósitos de Ruy Duarte de Carvalho com a produção de uma vaga de escritores que se apoiam no recurso do deslocamento - quase sempre simbólico - para a criação de "estéticas híbridas", tão desejada pelas teorias ditas pós-coloniais e pós-modernas que se consolidam um pouco por todo o mundo. Embora seja ele um desses cientistas-escritores-viajantes da contemporaneidade, não encontramos em sua obra um elogio apriorístico ao deslocamento, como sucede em diversos escritores da chamada literatura mundial. Nele parece acesa a consciência de que, na generalidade da prática, "escrever é sempre partir" (2008, p. 121). E Ruy Duarte de Carvalho não deixa de revelar: "uma certa ficção [...] só me ocorreu depois de ter feito largas travessias" (2008, p. 19). Contra a tentação da superficialidade, persiste a conviç̧ão de que "quanto mais longínquas são as distâncias a percorrer [...] maiores são as ilusões que elas alimentam" (2009, p. 16).

A prática antropológica com certeza reforça uma certa acuidade que não se compadece da mirada ligeira que orienta o turista. Mas o seu projeto vai além do exercício do etnógrafo convencional. Para além das pesquisas de campo e das viagens cultivadas pelo escritor, inscreve-se em seu trabalho o projeto de uma etnografia do processo de produção institucional dos espaços. Ao situar boa parte de suas narrativas no Sudoeste de Angola e no Noroeste da Namíbia, onde encontrou populações que poderiam identificar-se com esse "outro" radical que lhe tem estimulado a reflexão sobre o lugar de Angola no mundo e do mundo em Angola, o autor verticaliza a alargamento geográfico iniciado nos anos 60 pela literatura nacional. As visitas a lugares "outros" permitem-lhe escrutinar as aporias do saber ocidental e colocar em causa a ideia de universalidade que predomina desde a consolidação da expansão europeia:

a paisagem colocou-me questões: para lidar com ela, para entendê-la, para fazer da paisagem e da sua decifração o lugar da vida, e na vida, só sabendo como a viam, liam, diziam, os que a olhavam a partir de outras línguas, de outras linguagens, de outros entendimentos moldados por essas mesmas paisagens e por essas mesmas línguas. arranjar uma maneira de dizer dessas paisagens, em português, o que noutras línguas se diria delas ou o que elas diziam noutras línguas. como aliás não podia deixar de ser.

(2008, p. 20) 
Desse modo, ele, sem qualquer concessão ao pensamento colonial, também traz para a discussão as formas de combate utilizadas pelo discurso hegemônico no pós-independência. Anima-o o desejo de revelar os limites do que surge como libertador, ou seja, a aposta num discurso que identifica o "nacional" com uma parcela do todo que deve ser o país. Se, como mais atrás anunciamos, a configuração Cidade Alta e/ou as ruas de alcatrão foi identificada pelos contestatários dos anos 60 como um poder a ser enfrentado, a partir de meados da década de 1970 outra região era apresentada como uma imagem do novo centro: os musseques, que passariam a representar Luanda, por sua vez assumida como a metonímia de Angola.

A relevância dessa mudança está evidenciada no tributo prestado por Ruy Duarte de Carvalho em 2005 a José Luandino Vieira e a poetas ligados ao movimento "Vamos descobrir Angola". Em conferência realizada na Universidade de Coimbra, ele menciona a importância de Aires de Almeida Santos e Ernesto Lara Filho e o impacto que Luuanda representou na sua "conversão à condição de Angolano". A eloquência de seu testemunho é indiscutível:

[...] me remetia, com a carga emotiva de um sobressalto e de um sublime encontro, a um livrinho que dois anos antes, em 1963, tinha por dois ou três dias aparecido à venda nas livrarias de Luanda. O livrinho em questão chamava-se Luuanda e era de autoria do escritor angolano José Luandino Vieira. Ora a esse livrinho e a alguns versos de Viriato da Cruz, de Aires de Almeida Santos, bem como a algumas crônicas de Ernesto Lara Filho, eu devo o gole de consciência, pela via do arrepio, de uma alma Angolana que então em mim se veio acrescentar à consciência prévia de uma razão Angolana e foi responsável pela minha conversão à condição de Angolano (2008, p. 13-14)

Essa comovida e comovente confissão confirma a legitimidade do projeto literário que, com suas raízes fincadas na metade do século XX, colocava em pauta questões ligadas à identidade cultural e tinha na articulação entre o projeto ético e o projeto estético um vetor constitutivo. A validade da proposta pode ser apreendida na conversão de Ruy Duarte de Carvalho, como está explícito em sua reflexão também acerca de "um enorme e definitivo respeito pela literatura" (2009, p. 14).

Se assim é, qual o sentido da mudança que ele impõe aos ventos que vão orientar a sua trajetória? Se reconhece a dimensão libertária da literatura que coloca Angola em cena pela voz dos seus, ele não valida o pacto com outras exclusões que seria institucionalizado depois da independência. Contra a implantação dessa outra hegemonia, Ruy Duarte de Carvalho toma a palavra, como cidadão, como intelectual e como artista. Nas intervenções de caráter cívico, a contundência era constante: 
Eu, cá para mim, há coisas que entendo capitais para o destino de Angola, e do nosso nela, e a que só tenho acesso indo ao encontro da substância delas fora da Mutamba, quer dizer, fora da cervejaria Biker, ou da Assembleia Nacional, ou dos corredores dos Ministérios e dos escritórios das organizações internacionais (2008, p. 245).

A convicção de que era fundamental uma espécie de contraponto eloquente às dinâmicas vividas em Luanda plasmava-se em seus textos literários:

Regressei dessas fronteiras setentrionais do deserto com a sensação plena de estar lançado num espaço hostil, agitado, e em perigo, exasperado quase, desamparado no cinzento e no frio da cidade, a surpreender rajadas cortantes de desconforto nas esquinas das ruas, a sentir a incidência da desmunição geral, da indigência, da energia toda investida na apropriação vital e na afronta que a pode acompanhar: privar o outro, até, para garantir o essencial à própria vida (2000, p. 100).

Nessas geografias, ele alimentava o seu desassossego e apurava o seu método de investigar, independentemente da área do conhecimento em que investia. Cenários de constantes migrações ao longo da história, impuros por excelência, porque sempre situados em fronteiras físicas ou simbólicas, e colocados à margem por poderes imperiais, nacionais e transnacionais, os espaços celebrados ${ }^{4}$ pelas narrativas de Ruy Duarte de Carvalho possuem não apenas uma vocação histórica, mas transdisciplinar:

Do eco das migrações, dos destinos que excedem gerações, impõem rumos a que a espécie aponta, e rotas à toa ditadas pelo tempo, no útero do tempo, emergiu para mim uma voz então, primordial e fresca, frágil como o orvalho das paisagens despovoadas na aurora das eras, na idade da vida orgânica contida ainda só no destino a haver da água e das pedras. "O que faz você aqui?" (2000, p. 154)

Buscar respostas para essa pergunta foi um dos fins perseguidos por Ruy Duarte de Carvalho, antes mesmo que ela surgisse assim tão claramente elaborada em Os papéis do inglês. Como se as veredas percorridas levassem para frente mas sem reduzir a importância guardada na matriz que originaria a trilogia Os filhos de Próspero. Inquirir acerca do que se faz num determinado lugar pressupõe olhar à volta e perceber não só a sua inquietação mas também a dos outros, principalmente desses "outros" que por ali andam e guardam outros modos de percepção do mundo. Daí ser indispensável saber de certas diferenças que o desejo de harmonia subjacente às utopias não pode encobrir:

para estes pastores tudo estava a passar-se dentro de uma ordem de continuidades que não era nem a dos nacionalistas angolanos segundo o mapa de cada um dos movimentos, nem a daqueles que eram portugueses ou tinham seguido o 
destino de Portugal, nem a do próprio, o Trindade, devolvido de novo agora ali às lógicas pastoris mas depois de ter visto muito mundo à volta... $(2009$, p. 201)

Protagonista da última narrativa de Os filhos de Próspero, Trindade pode ser visto como a corporificação da opção pela radicalidade que foi conduzindo a trajetória de Ruy Duarte de Carvalho. Obcecado pela descentralização do olhar, ele procura estratégias de escrita (e pensamento, é óbvio) que acionam uma espécie de câmera em movimento. Dessa maneira, ao deslocamento do ângulo de observação da realidade nacional ele fará corresponder uma modificação do tipo de personagem até então vigente nas letras angolanas. Nem os heróis exemplares que convencionalmente a militância elege, nem os excluídos empenhados na instituição de uma certa ética da sobrevivência vão povoar o imaginário que ele fecunda. A partir desses outros territórios e na companhia de personagens "outros", o autor transita do digressivo, perscrutando a longa história e as manipulações que dela são feitas em seus sucessivos regimes, para uma literatura antecipativa:

Vir aos lugares não para vê-los só, nem só para reconstituir-lhes passados, nem registrar presentes, mas para cobrar-lhes futuros também. A apropriação de um lugar não passa só por pisá-lo e poder, a partir daí, recordá-lo. Será também poder, a partir de então, reter-lhe a impressão de um qualquer futuro, simultâneo ao meu (2010, p. 382).

Mais uma vez, entre a pesquisa etnográfica e o exercício literário instala-se uma espécie de confluência: em seu critério de seleção contam a mobilidade e um certo gosto pelo que se demarca da autoctonia como capital. E é interessante perceber que nos laços que se procura tecer não se esgota a relação criador/criatura. Como se, pelo fato de terem sido alheados do processo de construção de memórias imperiais e nacionais, cada uma delas marcadas por fabricações discursivas e esquecimentos próprios, os pastores, "à volta de uma fogueira, disso estou certo", assomassem à cena como "interlocutores mais imediatamente aptos a entender questões de expansão e de sucessão do que os que vier ter entre as paredes de um apartamento, em Luanda ou em São Paulo" (2010, p. 283).

A tematização de tal cumplicidade e a sua cenarização - que indicia a inviabilidade de uma identificação total - estão na base de uma "literatura de fronteira" (2008, p. 22), não apenas pela insólita combinação de gêneros que dali resulta, mas também e sobretudo pelo fato de tornar a paisagem "em língua maior", que se transmuda em voz, para, finalmente, perturbar "a expressão do poder que a língua também é" (2008, p. 22).

Partindo de um interesse particular pelas "paisagens de fronteira" (2008, p. 21), que em seu projeto são as paisagens de culturas subalternizadas, aquelas que não possuem representatividade política nem instrumentos de poder que lhes permitam assegurar sua dignidade ou mesmo sobrevivência, Ruy Duarte aponta as fissuras de um projeto modernizante que nem as boas intenções de alguns puderam prevenir 
ou minimizar. É o que vê como uma espécie de herança armadilhada que se imiscuiu no programa da nova nação, especialmente após 1992, quando se consolidam "legitimidades" raciais, por um lado, e se elaboram caricaturas de "primitividades" ou de "autenticidades" (2008b) prontas a satisfazer a sede de consumo do turismo étnico, cultural e científico do atual mundo global. Sem perder de vista o domínio material e simbólico consolidado pela expansão imperial, ele enceta uma espécie de busca do espaço perdido, lugares "outros", compostos de "tesouros" e personagens que devem ser ouvidos antes de seu completo desaparecimento. Em seu pensamento, contudo, não figura a ideia de que as populações desses lugares clamem por salvação. Pelo contrário, Ruy Duarte de Carvalho apenas procura demonstrar, por diversos ângulos, e não sem ironia, que o centro, nunca aberto ao questionamento de suas certezas, depende da urgente incorporação de temporalidades "outras". Em Vou lá visitar pastores, na imaginária interlocução com o amigo jornalista, o aviso se insinua:

Preparado para enfrentar o presente kuvale? Vamos a isso... Mas é preciso chegar até lá, ao espaço onde esse mesmo presente se te há-de revelar, não há tempo sem espaço e sem movimento, é essa a condição de todas as percepções e de todas as relatividades. Muito objectivamente e no nosso caso, aliás, vai ser preciso, até, cumprir um caminho bem físico e bem concreto, quanto às suas referências, para que possas ver-te introduzido no quadro, no enquadramento, desse presente que vais pretender identificar como o dos 'outros' e acabará inevitavelmente, espero, por marcar também o teu. Serão de facto múltiplos os presentes com que irás confrontar-te. Cada sujeito encontrado, cada homem, cada boi, cada paisagem, cada pedra, andará vivendo o seu, e eu, que te sirvo de cicerone, o meu. (2000, p. 103).

Em Desmedida, a advertência é explicitada:

Há gente aqui, não prevista nas Escrituras, e vai ser necessário enquadrar esta parcela da humanidade na história geral do gênero humano. (2010, p. 199)

Em colocações como essas, que se multiplicam pelo seu trabalho, sente-se o eco da hipótese de Milton Santos, para quem o espaço é a acumulação desigual de tempos (2007). Dessa certeza deriva outra, a de que a instituição científica ocidental e ocidentalizada não se apresenta como alternativa efetiva ao universo político, extremamente tóxico, mas sim o seu braço direito, como eufemismo materializado de uma empreitada que contribuiu para fazer corresponder à ocupação territorial a ocupação dos imaginários. Noutras palavras, o autor sabe que qualquer encontro com as paisagens pressupõe um confronto, quase sempre tenso, com a bibliografia que nelas se inspirou e/ou que delas deu conta no mercado de ideias e sentimentos que a globalização movimenta.

Nesse confronto entre paisagem e texto, que sobre Ruy Duarte de Carvalho exerce um produtivo fascínio, podemos localizar algumas 
matrizes de seu trabalho. Em Vou lá visitar pastores, o ensaio se tece com as referências incorporadas de uma vasta bibliografia que ele combina com a sua própria fala dirigida a um suposto amigo. Em Desmedida - luanda - são paulo - são francisco e volta - crônicas do Brasil, na incursão que faz aos sertões brasileiros (e a São Paulo, onde também se detém e demora a sua atenção), o olhar é temperado pelas muitas leituras que lhe abrem, relativizam, desmentem tantos aspectos de um Brasil que já na adolescência lhe chegava pelos livros e revistas comprados pelo pai em Moçâmedes. O diálogo texto/viagem/texto ali resulta de uma singular rede de dados em que o processo de representação se alimenta de muitas fontes. Nas palavras de Clara Rowland:

É a partir daqui, como veremos, que Desmedida irá desenvolver uma narração que cruza ecos literários com a narrativa de viagens num permanente confronto com o modo como a linguagem se articula com os mundos que nomeia - a "extracção" que tanto ocupa a obra poética do autor. [...] E o percurso pelas paisagens ditas não pode senão levar à interrogação da linguagem a usar numa escrita que fala de e com outras vozes. Será também esse o diálogo de Desmedida: o que vai encenando diferentes tons, colocações e destinações de acordo com o mapa da viagem, testando a elasticidade de uma prosa sempre dinâmica, deixando para o fecho o "rasgo ético de uma bibliografia comentada" a explicitar a biblioteca de referências que a narração foi transportando (2011).

Ao materializar uma espécie de reencontro com a terra que a leitura lhe apresentara, Ruy Duarte de Carvalho materializa também um plano de redimensionamento espacial no sistema literário angolano. Se ficamos apenas no conjunto das narrativas, temos uma sequência de ampliações: entre Como se o mundo não tivesse leste e Os papéis do inglês, passando por Vou lá visitar pastores, o deslocamento envolve o Sul de Angola; em As paisagens propícias, o Norte da Namíbia é incorporado no mapa das terras por onde circulam as personagens; em Desmedida, o salto é sobre o Atlântico, e o Brasil, ganhando corporeidade textual, oferece-se como uma espécie de espelho capaz de antecipar as transformações que podem estar guardadas para o futuro no quadro, ainda, da expansão ocidental em curso. Nesse alargamento do espaço nota-se um notável esforço de reflexão para melhor perceber as continuidades e contiguidades de um território em tudo convulsionado por uma sucessão de crises. Nas pontas o reiterado compromisso de não apreender o "outro", pois que em todo o percurso presentificam-se os sinais de um projeto que pretende "consumir o curso e o discurso das viagens" (2010, p. 388), como ele próprio declara, mas aprender com o outro.

Há, assim, dois grandes tipos de deslocamentos que rivalizam em sua obra: o que conduz à confiscação da paisagem, e dos tempos que lhe são inerentes, e o que é motivado pelo desejo e pela necessidade de escuta. Até mesmo o mais vigilante dos viajantes pode cair na armadilha do 
primeiro modelo. Em pleno embate com a paisagem, nas páginas iniciais de Os papéis do inglês, o narrador de Ruy Duarte de Carvalho capta os riscos em que pode sucumbir o explorador que não desconfia de suas certezas:

Saí sozinho, logo que cheguei, para fotografar pedras à volta do acampamento, no regresso atravessei uma linha de água em sítio errado e desfiz o rumo, mantive as cabeças dos morros à esquerda mas ultrapassei a zona, internei-me em mata sempre baixa mas cada vez mais densa, deixei de ver à volta, fui ter muito à frente, quer dizer, perdi-me. Subi a uma pedra, vi a antiga pedreira de mármore já assim tão perto, do acampamento só se lhe vê é a cabeça branca. Retrocedi. Agarrei então o curso de uma outra mulola, havia de vir ter até ao rio, rodeei um sombrio cemitério, entalei no cinto um ramo de folhas verdes, e aí apanhei um caminho de bois que acabou por trazer-me a estas nascentes aqui ao lado. Andei às voltas por me julgar bastante, em terreno alheio (2000, p. 11).

Após desenhar os contornos do equívoco por via de uma linguagem espacializada, o narrador sintetiza, em uma frase, o erro do viajante ("Andei às voltas"), apresenta um dos grandes malefícios dos cientistas e dos produtores culturais, mesmo quando bem-intencionados ("por me julgar bastante”), e, descontruindo a ilusão de que tudo é familiar ou pelo menos domesticável, reafirma a ideia de "terreno alheio".

O dever de humildade, implícito nesse percalço, contudo, não o dispensa de outra obsessão: a qualidade. Ruy Duarte de Carvalho exerce ao longo de toda sua obra, literária, científica ou cinematográfica, o direito à exigência: "há muito tempo que me atrevo a dizer que a intelectualidade científica dominante só nos respeitará mesmo quando se vir obrigada a incorporar na ciência global alguma coisa que saia de uma matriz inequivocamente nossa" (2008b).

Ligado a esse direito, que é assumido por Ruy Duarte como compromisso de vida, o segundo tipo de deslocamento está, entre outras coisas, na base da "contra-descoberta", da "volta paradigmática e pragmática" que o autor anuncia de maneira mais completa, embora não finalizada, em $A$ terceira metade. A partir dos espaços e dos olhares de personagens como Nambalisita e Trindade, promove-se uma decisiva inversão:

o mar visto de longe e a massa de cacimbo que o cobre ou sobe já, dessas coisas você sabe, continua a ser a tua geografia......... para nós, o deserto, faz falta é quando estás noutro lugar..... quando estás lá você não dás nem conta. quando não estás sentes-lhe a falta mas não é de te exaltares no deserto que tu precisas, nem é isso que te faz correr para lá...... é estar lá só, é estar antes mais talvez onde possa ser ele a ver-te, o deserto, e não tu a ele. (2009, p. 270).

Contra o cultivo da facilidade que o incomoda, tanto na gestão da política, quanto na elaboração estética, insere-se a "paixão do deserto" (2000, p. 104), que, segundo o próprio, nasce de uma "atração pelos abis- 
mos" (2009, p. 269). Em seus textos, ela está sempre ao serviço de uma crítica aos poderes instituídos, colonial e nacional, científico e político, todos eles instrumentalizados pelo "mundo que a expansão ocidental criou", e que, em torno de ideias voltadas para a superioridade civilizacional e/ou para a legitimidade racial e étnica, reduziram o horizonte da longa história e de seus protagonistas.

O estreito laço que une esses espaços alheios à singularidade de personagens "outras", figuras da alteridade radical, porque conotadas com discursos arcaicos que são desprezados pelos poderes e pelo saber dominante, constitui um dos eixos mais produtivos para a montagem de Filhos de Próspero, a trilogia formada por Os papéis do inglês, As paisagens propícias e A terceira metade. Para a radicalidade de sua proposta, era preciso achar um lugar e "aquela vertente entre o platô e o deserto era um lugar propício à conjugação daqueles três singulares caracteres, SRO, o Trindade e o K órfãos do império os três" (2009, p. 306). Figuras como o mucuísso Trindade, indivíduo que não é branco nem banto, e simultaneamente "domesticado tanto pela incidência banta como pela incidência ocidental", sendo considerado por ambos como um primitivo, podem ser vistas como um modelo de lugar no projeto intelectual de Ruy Duarte de Carvalho. De tal modo que a consciência de Trindade será recorrentemente comparada a um vasto e ignorado continente:

um absoluto e imprevisto olhar, portanto e de qualquer maneira............. e, para o autor, talvez, uma terceira metade da mesmíssima coisa que tinha andado a tentar querer dizer antes, dando notícia de outros olhares...... até encarar o risco de pretender aventurar-se agora, explorador impenitente, pelo ignoto continente de uma consciência assim (2009, p. 23).

Fazendo confluir forma e temática, o autor não se limita a situar seu discurso no "confronto entre a palavra criativa e as outras, mas numa fronteira entre duas modalidades de palavra acrescentativa, como o Trindade preferia chamar-lhe, entre a palavra que demonstra e aquela que representa” (2009, p. 383). Seu projeto não invisibiliza o indivíduo, como se deu na produção colonial, nem dá voz ao oprimido, como sucedeu na estética anticolonial. Levando ao extremo a identificação com esse "outro" radical em vias de extinção, o autor procura ouvi-lo e, secundando-se, traduzi-lo.

Em A terceira metade, escancaram-se a natureza e a pretensão de seu projeto. Nesse processo, protagonizado por Trindade e mediado pelo narrador, e em que se articulam as funções desencantada e utópica, e as formas regressiva e antecipativa, o autor propõe uma gramática com 7 grandes grupos de palavras, na qual se apoiaria o tal giro paradigmático. Trata-se de uma proposta ambiciosa, efetivamente alternativa, que se fundamenta no gesto de escuta e na ponderação dos implícitos que os lugares excluídos ainda guardam.

É dessa maneira que Ruy Duarte mergulha nas cosmologias e 
cosmogonias da África Austral para, na qualidade de tradutor de mundos, apresentar um convite ao questionamento e à denúncia, e, ao mesmo tempo, um alerta para aquilo que ele denomina como "a emergência pontual do inédito" (2010, p. 190), os tais tesouros que também veio conhecer no Brasil, no já citado Desmedida. Aquele "muito mundo à volta", que repercute na formação do Trindade, dando contornos próprios ao seu ponto de vista, também intervém no modo de apreender as coisas de Ruy Duarte de Carvalho, exigindo-lhe uma atenção que dê conta das continuidades, das rupturas e das contiguidades - palavra fundamental em seu trabalho. $\mathrm{Na}$ vi(r)agem epistemológica que propõe, pode ser protagonista o indivíduo "não só imediatamente iletrado mas também confessamente ignorante, capaz todavia de fraturar com um imenso brilho, enquanto brande o seu limitadíssimo vocabulário, todas as gramáticas do mundo" (2009, p. 81).

Assim, ao clamar pelo direito de existência e sentido a todas as geografias, "divinas, biológicas e mineirais até" (2008b), ele confere reconhecimento pleno a esse "outro" que, pensando "de maneira absolutamente diferente", poderia "conseguir ver certas coisas e certos fenómenos de uma maneira melhor e mais adequada à efetiva configuração do mundo, e que os ocidentais e os ocidentalizados, nesse caso, é que teriam a aprender com o "outro", e que isso acabaria por convir a todos" (2008b). Como convém a tantos a leitura de sua obra, completamos nós.

\section{REFERÊNCIAS BIBLIOGRÁFICAS}

ACHEBE, Chinua. A educação de uma criança sob o protetorado britânico, São Paulo: Companhia das Letras, 2009.

CANDIDO, Antônio. Formação da literatura brasileira: momentos decisivos. Rio de Janeiro, Ouro sobre Azul, 2006.

CARVALHO, Ruy Duarte de. a câmara, a escrita e a coisa dita... fitas, textos e palestras. Lisboa: Cotovia, 2008.

. As paisagens propícias, Lisboa: Cotovia, 2005.

. A terceira metade. Lisboa: Cotovia, 2009.

. Chão de oferta. Luanda: Culturang, 1972.

. Como se o mundo não tivesse leste. Lisboa: Cotovia, 2008 [1977].

. Desmedida. Rio de Janeiro: Língua Geral, 2010.

. Hábito da Terra. Luanda: UEA, 1988.

. Lavra. Lisboa: Cotovia, 2005.

. Ondula, savana branca. Expressão oral africana: versões, derivações, reconversões. Lisboa: Sá da Costa, 1982.

. Os papéis do inglês. São Paulo: Companhia das Letras, 2000. 
. “Tempo de ouvir o 'outro' enquanto o 'outro' ainda existe antes que haja só o outro”, 2008b. Disponível em: <http://www.proximofuturo.gulbenkian.pt/blog/tempo-de-ouvir-o-outro-enquanto-o-outro-ainda-existe-antes-que-haja-so-o-outro> Acesso em 15 dez. 2015.

. Vou lá visitar pastores. Lisboa: Cotovia, 1999.

CONRAD, Joseph. No coração das trevas, São Paulo, Hedra, 2008 [1902].

MACÊDO, Tania. Luanda, cidade e literatura. São Paulo: Editora UNESP;

Luanda: Nzila, 2008.

NOA, Francisco. Império, mito e miopia: Moçambique como invenção literária.

Lisboa: Caminho, 2003.

PRATT, Mary Louise. Os olhos do Império: relatos de viagem e transculturação. Bauru: Editora da Universidade do Sagrado Coração, 1999.

ROWLAND, Clara. Recensão a Desmedida. Luanda, São Paulo, São Francisco e volta. Buala, 2011. Disponível em: http://www.buala.org/pt/ ruy-duarte-de-carvalho/recensao-a-desmedida-luanda-sao-paulo-sao-francisco-e-volta. Acesso em: 10 dez. 2015.

SAID, Edward W. Cultura e imperialismo. São Paulo: Companhia das Letras, 1999.

. Orientalismo. O Oriente como invenção do Ocidente. São Paulo: Companhia das Letras, 2001.

SANTOS, Milton. Pensando o espaço do homem. São Paulo, Edusp, 2007 [1982].

TOPA, Francisco. Luuanda há 50 anos - críticas, prêmios, protestos e silenciamento. Porto: Sombra pela Cintura, 2015.

Recebido para publicação em 13/09/2015

Aprovado em 25/02/2016

\section{NOTAS}

* Rita Chaves é professora de Literaturas Africanas de Língua Portuguesa da Faculdade de Filosofia, Letras e Ciências Humanas da USP. Nazir Ahmed Can é professor de Literaturas Africanas de Língua Portuguesa da Faculdade de Letras da UFRJ

2 Sobre a obra e sua história também na cena política, pode-se consultar o importante livro de Francisco Topa: Luuanda há 50 anos - críticas, prêmios, protestos e silenciamento, Porto: Sombras pela Cintura, 2015.

3 Trata-se do poema "Sul”, com que abre Chão de oferta, de 1972.

4 No sentido dado por Chinua Achebe: a celebração enquanto restabelecimento de uma "presença" (2009, p. 116). 